\title{
Assess the level of implementation of Patient Safety Culture in a Tertiary Care Hospital in Sri Lanka.
}

\author{
P.H.Wijenayake ${ }^{1}$, M.S.N Manathunga ${ }^{2}$, Y. J.Samarasinghe ${ }^{3}$, I.W.M J Wickramarathne ${ }^{4}$, Abhayaratne, \\ A.J. ${ }^{5}$ R.G.K.Vijayakumara ${ }^{6}$ \\ ${ }^{1}$ Ministry of Health, ${ }^{2}$ Teaching Hospital Mahamodara, ${ }^{3}$ Ministry of Health, ${ }^{4}$ District General Hospital Trincomalee,,${ }^{5}$ Base Hospital \\ Meerigama, ${ }^{6}$ Teaching Hospital Mahamodara
}

DOI: $10.31364 / \mathrm{SCIRJ} / \mathrm{v} 8.14 .2020 . P 0420759$

http://dx.doi.org/10.31364/SCIRJ/v8.i4.2020.P0420759

\begin{abstract}
Background: Patient safety is a major concern for all health care providers worldwide. For creating patient safety culture the attitudes, values and beliefs of the members of the health care institutions towards patient safety should be improved. The study is expected to assess the culture of patient safety at Teaching Hospital Mahamodara - Galle (THM) and, Hospital Survey on Patient Safety Culture (HSOPSC) questionnaire was used as the study instrument. The responsibility of creating a culture of safety belongs to all employees in a hospital; however, It will be successful only the involvement of senior management. In order to understand where to focus efforts in building this environment, hospital senior management must understand the opinions and beliefs of the employees regarding the safety culture of their hospital, before initiating a health and safety program.

Methodology: The study design was a hospital based descriptive cross-sectional, using HSOPSC questionnaire. It was expected to measure the 12 dimensions of the patient safety culture of THM. The data collecting instrument which was a self-administered questionnaire, distributed among heath care staff including medical consultants, nurses, midwives, and para-medical staff. A total of 279 questionnaires were returned out of 416 (response rate 67\%). Data were summarized as percentages, means and standard deviations. This study used HSOPSC data entry and analyzing tool for the purpose of statistical analysis.

Results: In average $56 \%$ responded positively for the 12 patient safety culture dimensions of the HSOPSC survey. It was lower than the findings of the Agency for Healthcare Research and Quality (AHRQ) (65\%), in 2018. "Teamwork within unit" scored the highest positive response rate that was similar to the US findings. The lowest percentage of positive responses were obtained by the dimension 'Staffing". Forty seven percent respondents graded overall patient safety as 'excellent' or 'very good' while $48 \%$ graded it as 'acceptable'. Seventy eight percent of respondents had not reported any adverse event during last 12 months.

Conclusions: The HSOPSC tool is a practical avenue to understand the health and safety culture in THM when initiating health and safety programs in order to understand the critical areas that should be focused. The results show that, in general, hospital staff of THM feels positively towards patient safety culture within the hospital. In addition, THM should enhance the education and should move towards a blame-free culture to improve the adverse event reporting. The showed discrepancies between US data and THM data suggest that cultural uniqueness is an important factor to give much better attention when applying safety culture tools to gather data in different cultural settings.
\end{abstract}

Keywords: Patient safety, Patient safety culture, Hospital, Sri Lanka

\section{Introduction}

There are many definitions for patient safety; however, most of definitions cover almost the same area of patient care. Patient safety is defines as "the prevention of error and adverse effects to patients associated with health care" and "to do no harm to patients" by the World Health Organization (WHO) (1). Patient safety culture is, generally how healthcare workers perceive and value patient safety in their organizations. Patient safety culture can be defined as status made of beliefs and assumptions, within the members of the organization towards patient safety. Patient safety culture emphasizes the reporting, analysis and prevention of errors that lead to adverse health care events. (2)

Mainly three quality domains of patient safety are found in literature, namely: structure, process and outcome. However, this grouping cannot be taken as definitive but create a practical framework for approaching the safety topics. Furthermore, the topics covered activities and areas that could impact the health system at many different levels. The key structural issue that that impact patient safety is the inadequate number of qualified healthcare providers worldwide. Globally, 57 countries have an estimated deficit of 2.4 million doctors, nurses and midwives and thus face substantial challenges in meeting health-related Millennium Goals to ensure the quality and safety of their health systems (3). Two other key structural factors that may affect patient safety includes the organization's culture, which composed of shared attitudes, values and norms related to patient safety and human factor engineering. Some of the process domain factors includes: misdiagnosis of disease conditions; lack of adequate follow -up of important test results; and,

www.scirj.org

(C) 2020, Scientific Research Journal

http://dx.doi.org/10.31364/SCIRJ/v8.i4.2020.P0420759

This publication is licensed under Creative Commons Attribution CC BY. 
counterfeit and substandard drugs, defined as those that are mislabeled, missing active ingredients or include wrong active ingredients, poses a major risk to patient safety. Adverse events which can be any harmful event due to an interaction with the healthcare system are categorized as outcome domain.

By evaluating the incident reporting and analysis of adverse event reporting systems, the organization can obtain an idea about to what extent the patient safety culture is established within their organizations and also to detect the error prone areas and places to intervene for further improvements. Under the light of measured components related to patient safety culture new safety programmes can be started and the progress of the existing programmes can be measured. Employee surveys, qualitative methods such as in depth interviews and focus group discussions or combination of both can be applied to measure the patient safety culture. Hospital employee based findings provides the front line evidence on adverse practices which the management can intervene.

Healthcare managers' strong leadership in identification of patient safety as a priority area is crucial to establishing a positive health care culture in health care organizations. Healthcare managers' commitment, motivation and the leadership style will affect to change the attitudes and behavior of rest of the work force. No blame, no shame and no punitive practice and mutual trust; are some of the components of the positive patient safety culture. Healthcare workers who are involving in processes and care providers have insight that mistakes can occur anytime and anywhere, therefor acceptance that mistakes can happened by all levels of staff in the organization; and, ability to recognize, quick counteract and learn from adverse events will improve the patient safety culture.

\section{Background information}

In 1995, Medical Practice Study (HMPS) (4) results were published. However, this was not the initiative step to look into the adverse events in healthcare organizations, it helped to define the standards to which the workers should adhere and take measurements against that can be used to make policies and incorporated in evidence base practice. The methods used in the Harvard Medical Practice were based on the 1997 California medical insurance feasibility study (5). Application of these methods in the health care organizations research reveals valuable information on adverse events. Harvard Medical Practice Results showed adverse events occurred in $3.7 \%$ of the hospitalizations and $27.6 \%$ of the adverse events were due to negligence. Although $70.5 \%$ of the adverse events gave rise to disability lasting less than 6 months, $2.6 \%$ caused permanently disabling injuries and $13.6 \%$ led to death.

On December 1, 1999, the Institute of Medicine (IOM) published To Err is Human: Building a Safer Health System, revealed that an estimated 44,000 to 98,000 people die annually from medical errors (6).According to the Report, "more people die in a given year as a result of medical errors than motor vehicle accidents $(43,458)$, breast cancer $(42,297)$, or AIDS (16,516)" (p.22). The Report also estimates that total national costs encompassing lost income, lost household production, dis-ability, and health care costs of preventable adverse events are estimated to be between \$17 and \$29 billion annually, 50\% of which are direct health care costs. The Report has drawn strong responses from Congress, the White House, and health professional organizations. The medical errors issue is anticipated to receive a lot of attention by the federal government and Congress in the year 2000.

In year 2000 the chief medical officer, professor Sir, Liam Donaldson published “An Organization with a Memory"(7). This urged the National Health Service (NHS) in England to learn from other safety - critical sectors and to modernize its approach to learning from failure. This report showed that the great majority of NHS care is of a very high clinical standard, and serious failures are uncommon in relation to the high volume of care provided every day in hospitals and in the community. Yet, where serious failures in care do occur they can have devastating consequences for individual patients and their families, cause distress to the usually very committed health care staff involved and undermine public confidence in the services the NHS provides. In addition, the cumulative financial cost of adverse events to the NHS and to the economy is huge. Most distressing of all, such failures often have a familiar ring, displaying strong similarities to incidents which have occurred before and in some cases almost exactly replicating them. Many could be avoided if only the lessons of experience were properly learned.

In January 2002, the Executive Board of World Health Organization extensively discussed the subject of patient safety and recommended a resolution to the Fifty-fifth World Health Assembly. Resolution WHA55.18, adopted by the Health Assembly in May 2002, emphasized the value of paying more attention on patient safety measures based on evidence and availability of safe drugs, medical equipment and technology of the member countries (8). Further, it requested the Director-General of World Health Organization to develop global norms and standards; to promote the framing of evidence-based policies and to develop mechanisms into practice patient safety measures internationally; to encourage research on the subject; and to support Member States in several key areas.

In 2004, World Health Organization launched the World Alliance for Patient Safety (9). The World Health Organization (WHO) and its partners announced A series of key actions were introduced by the WHO to minimize the injuries and adverse events that experienced by the patients during healthcare, by launching the World Alliance for Patient Safety. The alliance had a firm objective to deliver six programs within coming next two years. The objective were: global patient safety challenge, focusing over $2005-2006$ on health-care associated infection; patients for patient safety, involving patient organizations and individuals in alliance work; taxonomy for patient safety ensuring consistency in the concepts, principles, norms and terminology used in patient safety work; research for patient safety developing a rapid assessment tool for use in developing countries and undertaking global prevalence studies of adverse effects; solutions for patient safety promoting existing interventions and coordinating activity internationally to ensure new solutions are delivered; and, reporting and learning generating best practice guidelines for existing and new reporting systems and facilitating early learning from information available.

www.scirj.org

(C) 2020, Scientific Research Journal

http://dx.doi.org/10.31364/SCIRJ/v8.14.2020.P0420759

This publication is licensed under Creative Commons Attribution CC BY. 
In 2005, World Health Organization launched the first global patient safety challenge. (10). Among the components of the implementation strategy of the First Global Patient Safety Challenge "Clean Care is Safer Care" included: raising awareness globally of the impact of health care-associated infections on patient safety and promoting preventive strategies; inviting ministers of health from all WHO Member States to make a formal statement committing to address health care-associated infection in their country and, testing the implementation of the WHO guidelines along with selected actions from the other WHO strategies.(10).

\section{Justification}

In Sri Lanka, Ministry of Health has been actively pursuing to improve the patient safety and quality care of hospital services in response to the increasing medical errors, increasing media attention and public pressure. Preventive measures have been implemented to improve quality and safety mainly through establishing healthcare quality indicators for hospitals. Despite emphasis on patient safety, THM has not been made any attempt to evaluate patient safety culture so far. Therefore, assessing employees perception about safety culture and identification of factors that needs to be emphasized in order to develop and maintain the culture of safety among hospital staff is crucial.

\section{Objectives}

To assess the level of patient safety culture at Teaching Hospital Mahamodara -Galle, Sri Lanka and to identify factors affecting to it.

\section{Literature review}

There are multiple definitions for Organization culture. Generally it is characterized by the shared values, norms and tacit assumptions of members within an organization while others include more tangible characteristics such as social practice (11). Characteristics of a strong and proactive safety culture generally includes leadership, commitment to learning from errors; documenting and improving patient safety; encouraging and practicing teamwork; identification of potential hazards; using systems for reporting and analyzing adverse events; and, identifying employees as key players in improving rather than causing error (12). Safety culture is also characterized by: systematic data collection and reporting (13); establishing blame-free culture; leadership involvement (14); and, focus on systems (15).

Organization culture is an important determinant of patient safety in health care organizations (16, 17). Researchers of various countries have focused on measuring patient safety culture in healthcare organizations. There are many studies conducted in developed countries indicate a considerable percentage (10\%) of medical errors occur in hospitals (18). Although medical errors happen in countries at all levels of development, there is a fear that developing countries may be impacted disproportionately (19).

Medical errors are not necessarily the result of just one simple factor. A British study, for example, examined the complex array of medical mistakes within the National Health Service (NHS) hospitals. Some of the contributory factors they found includes: errors in diagnosis frequently made by inexperienced clinicians; poor medical records; poor communication between professional providers; insufficient input by consultant physicians into day-to-day care; and, lack of thorough evaluation of patients before discharging them out of the hospital. All those are considered as organizational factors, which if measured and monitored by administrators, could result in change to a hospital safety culture (20).

World Health Organization defines patient safety as "the absence of preventable harm to a patient during the process of health care" (21). Generally, this implies a discipline of coordinated efforts to avoid patient harm caused during the process of health care itself. During the past two decades patient safety has been increasingly accepted as an issue of global importance. However, the complexity of healthcare has made it even challenging to measure and, therefore, to design and to implement programs to address deficits in patient safety the new emerging term, could probably better explain this phenomenon. AHRQ explains the safety culture of an organization as, "the product of individual and group values, attitudes, perceptions, competencies, and pattern of behavior that determined the commitment to and the style and proficiency of an organization's health and safety management" (22). Organizations with all the above mentioned positive characteristics of a safety culture should then be considered truly committed to the value of patient safety.

Researchers have identified four factors from literature that characterize a safety culture: recognition of the risk error in the organization's activities; blame-free environment for reporting; collaboration across the organization; and, organizational resources for safety (23). The development of effective safety practices and that encourages and adherence to these practices and continuous learning from errors provides the basis for safer performance and the patient safety culture (24).

\section{Methodology \\ Study design}

This was a hospital based cross sectional descriptive study.

\section{Study setting}

The study setting was Teaching Hospital Mahamodara-Galle which is the main maternity hospital in Southern Province of Sri Lanka with bed strength of 364. It receives referral from District General Hospitals, Base Hospitals and District Hospitals of Southern Province. The hospital provides maternity, gynecology, neonatology, sub fertility service and out-patient services to the public.

\section{Sample size:}

The sample size was 416 which included all medical consultants, medical officers, and intern medical officers, dental surgeons, nursing staff, para medical staff and administrators.

\section{Exclusion and inclusion criteria}

www.scirj.org

(C) 2020, Scientific Research Journal

http://dx.doi.org/10.31364/SCIRJ/v8.i4.2020.P0420759

This publication is licensed under Creative Commons Attribution CC BY. 
Hospital staff who had worked more than three months at this hospital was taken as the eligible candidates for the study. Those who were on maternity leave and long-term leave excluded.

\section{Study instrument}

The questionnaire introduced by Agency for Healthcare Research and Quality (AHRQ) to measure the (patient safety Hospital Survey on Patient Safety Culture - HSOPSC) was administered to collect data, with few modifications. This is a validated questionnaire and used in many different countries. The questionnaire consists of 42 items that measure 12 patient safety culture composites. Each composite has 3 or 4 items. The response to each item in the questionnaire was assessed using a 5-point Likert scale ranging from 'strongly disagree' to 'strongly agree' and frequency from 'Never' to 'Always'. There were two single-item outcome variables: that were measured the overall patient safety on a scale of 'Excellent', 'Very good', 'Acceptable', 'Poor' and 'Failing'. Demographic data of participants consist of questions related to job category, work area, work experience and working hours per week. The questionnaire was kept in English, as most of the participant can understand English. However, a copy of questionnaire translated to Sinhala by an official translator was also attached. A paper-based questionnaire, consent form and information sheet were distributed to the selected participants. Staff members who were in long-tern leave were excluded from the survey.

Data analysis

HSOPSC data entry and analysis tool introduced by AHRQ was used to analysis the data, with prior permission. The demographic data, scores of patient safety culture dimensions and safety outcomes namely: the number of events reported and patient safety grade were summarized using descriptive statistics. In order to aggregate different survey questions, "Average Positive Response" was measured by comparing the percentage of positive responses (e. g. 'Agree, Strongly agree) to positively worded items ('People support one another in this unit') or negative responses (e.g. Disagree, Strongly disagree) to negatively worded items (e.g. 'we have safety problems in this unit').Summation of the items within the composite scales and dividing by the number of items was applied to compute the composite level scores.

\section{Ethical consideration}

Ethical clearance was taken from Ethical Review Committee of Faculty of Medicine, University of Ruhuna Sri Lanka.

\section{Results}

\section{Characteristics of respondents}

A total of 416 questionnaires were distributed; out of them 279 were responded, giving a response rate of $67 \%$. The highest respondents were nurses $(67.38 \%, \mathrm{n}=188)$. Many of the respondents' primary work was obstetric units $(49 \%, \mathrm{n}=137)$ Seventy six respondents $(27.24 \%)$ had worked in this hospital between one to five years. Ninety eight of respondents $(35.13 \%)$ had worked in the current unit between one and five years. Majority of respondents $(64.16 \%, n=179)$ had worked $40-59$ hours per week (Table 1$)$.

Table 1: Socio-demographic features and professional characteristics of respondents

\begin{tabular}{lc}
\hline Characteristics & $N(\%)$ \\
\hline Working unit & \\
Obstetrics & $137(49.10)$ \\
Surgery & $33(11.83)$ \\
Intensive care unit (any type) & $27(9.68)$ \\
Out Patient Department & $20(7.17)$ \\
Many different units /no specific unit & $18(6.45)$ \\
Anesthesiology & $15(5.38)$ \\
Laboratory & $11(3.94)$ \\
Pharmacy & $8(2.87)$ \\
Radiology & $2(1.08)$ \\
Medicine & $2(0.72)$ \\
Pediatrics & $2(0.72)$ \\
Administration /Management & $3(0.72)$ \\
Mental Health & $1(0.36)$
\end{tabular}

\section{Staff position}

Nurses

Medical Officers

Midwives

Medical laboratory technologists

Pharmacists

Cardiographers

Radiographers

Physiotherapists

Dental Surgeons
$188(67.38)$

33 (11.83)

25 (8.96)

$12(4.30)$

$6(2.15)$

3 (1.08)

3 (1.08)

$2(0.72)$

$2(0.72)$

www.scirj.org

(C) 2020, Scientific Research Journal

http://dx.doi.org/10.31364/SCIRJ/v8.i4.2020.P0420759

This publication is licensed under Creative Commons Attribution CC BY. 
Consultants

Administrators

Special Grade Nursing Officers

Time worked in the hospital

Less than 1 year

$1-5$ years

6-10 years

$11-15$ years

16-20 years

More than 20 years

Time worked in the current unit

Less than 1 year

$1-5$ years

6-10 years

$11-15$ years

16-20 years

More than 20 years

Typical working hours per week

Less than 20 hours

20-39 hours

40-59 hours

60- 79 hours

80-99 hors

More than 100 hours

Work experience

Less than 1 year

1-5 years

6-10 years

$11-15$ years

16-20 years

More than 20 years
$2(0.72)$

$2(0.72)$

$1(0.36)$

$32(11.47)$

$76(27.24)$

$55(19.71)$

$52(18.64)$

$41(14.70)$

$23(8.24)$

$70(25.09)$

$98(35.13)$

65 (23.30)

$26(9.32)$

$19(6.81)$

$1(0.36)$

$0(0.00)$

$55(19.71)$

179 (64.16)

$37(13.26)$

$2(0.72)$

$6(2.15)$

$10(3.58)$

$25(8.96)$

$72(25.81$

$65(23.30)$

$60(17.92)$

57 (20.43)

\section{Composite- level results}

Twenty two percent to seventy nine percent responded positively for the 12 patient safety dimensions and fifty six percent was the mean positive respondent rate for all dimensions. 'Staffing' ranked as the lowest positive response rate (22\%) while "the team work with in the unit" scored the highest positive response rate (79\%). Out of all 12 dimensions eight dimension's positive response rates were above $50 \%$ (Table 1$)$.

Figure1: Patient safety culture composite-level scores of THM

Note 1: The composite-level percentage of positive responses was calculated using the following formula: [number of positive responses to the items in the composite/total number of responses to the items (positive, neutral, and negative) in the composite] $\times 100$ Item- Level results

When it comes to item level results, item 'We are actively doing things to improve patient safety' got the highest positive percentage $(99 \%)$ while two items in teamwork within unit composite got $92 \%$ percent positive score. 'Staff in this unit work longer hours than is best for patient care go the lowest percentage ( $8 \%$ ) (Table: 2 ).

Table 2: Percent average positive response for an item-level and composite

\begin{tabular}{|ll|}
\hline Composite and items & \% positive \\
\hline Teamwork within unit & 92 \\
A1. People support one another in this unit & $\begin{array}{l}\text { When a lot of work needs to be done quickly, we work together as a team to get the work } \\
\text { A3. }\end{array} \quad \begin{array}{l} \\
\text { done }\end{array}$
\end{tabular}

www.scirj.org

(C) 2020, Scientific Research Journal

http://dx.doi.org/10.31364/SCIRJ/v8.i4.2020.P0420759

This publication is licensed under Creative Commons Attribution CC BY. 
A4. In this unit, people treat each other with respect

A11. When one area in this unit gets really busy, others help out

B1. My supervisor say a good word when he/she see a job done according to established patient 68 safety procedures

B2. My supervisor seriously consider staff suggestions for improving patient safety

B3. Whenever pressure build up, my supervisor wants us to work faster, even if means taking 33 shortcuts

B4. My supervisor overlooks patient safety problems that happen over and over

Organizational learning- continuous improvement

A6. We are actively doing things to improve patient safety

A8. Mistakes have led to positive changes here

A13. After we make changes to improve patient safety, we evaluate their effectiveness

Management support for patient safety

F1. Hospital management provides a work climate that promotes patient safety 64

F8. The actions of hospital management show that patient safety is a top priority 70

F9. Hospital management seems interested in patient safety only after an adverse event 52 happens

Feedback and communication about error

C1. We are given feedback about changes put into place based on event reports 59

C3. We are informed about errors that happens in this unit 73

C5. In this unit, we discuss ways to prevent errors from happening again 70

Frequency of evet reported

D1. When a mistake is made, but is caught and corrected before affecting the patient, how often 41 is this reported?

D2. When a mistake is made, but has no potential to harm the patient. How often is this 47 reported?

D3. When a mistake is made that could harm the patient, but does not, how often is this 45 reported?

Overall perception of patient safety

A10. It is just by chance that more serious mistakes do not happen around here $\quad 62$

A14. Patient safety is never scarified to get more work done 93

A16. We have patient safety problems in this unit 52

A17. Our procedures and systems are good at preventing errors from happening 69

Communication openness

C2. Staff will freely speak up if they see something that may negatively affect patient care $\quad 74$

C4. Staff feel free to question the decisions or actions of those with more authority 49

C6. Staff are afraid to ask questions when something does not seems right 49

Teamwork across units

F2. Hospital units do not coordinate well with each other 38

F4. There is good cooperation among hospital units that need to work together 61

F6. It is often unpleasant to work with staff from other hospital units $\quad 75$

F10. Hospital units work well together to provide the best care for patients 79

Staffing

A2. We have enough staff to handle the workload 31

A5. Staff in this unit work longer hours than is best for patient care $\quad 8$

A13. We work in 'crisis mode' trying to do too much, too quickly 32

Handoffs and transitions

F3. Things 'falls between the cracks' when transferring patients from one unit to another 35

F5. Important patient care information is often lost during shift changes 91

F7. Problems often occur in the exchange of information across hospital units 34

$\begin{array}{ll}\text { F11. Shift changes are problematic patients in this hospital } & 87\end{array}$

Non-punitive response to error

A8. $\quad$ Staff feel their mistakes are held against them 27

A12. When an event is reported, it feels like the person is being written up, not the problem 31

A16. Staff worry that mistakes they make are kept in their personnel file. 
Patient safety grades

Majority of hospital employees graded patient safety as 'acceptable' (48\%) while the percentage of employees who graded the level of patient safety as 'very good' or 'excellent' was $47 \%$ (figure 2 ).

Figure 2: Patient safety grades given by hospital employee with regard to their work unit

Note1: Total percentage does not add to $100 \%$ due to rounding.

\section{Number of events reported}

Vast majority (78\%) of respondents had not reported any adverse event during last 12 months while no respondent had reported more than five adverse events during last 12 months.

Figure 3: Number of events reported during last 12 months at THM

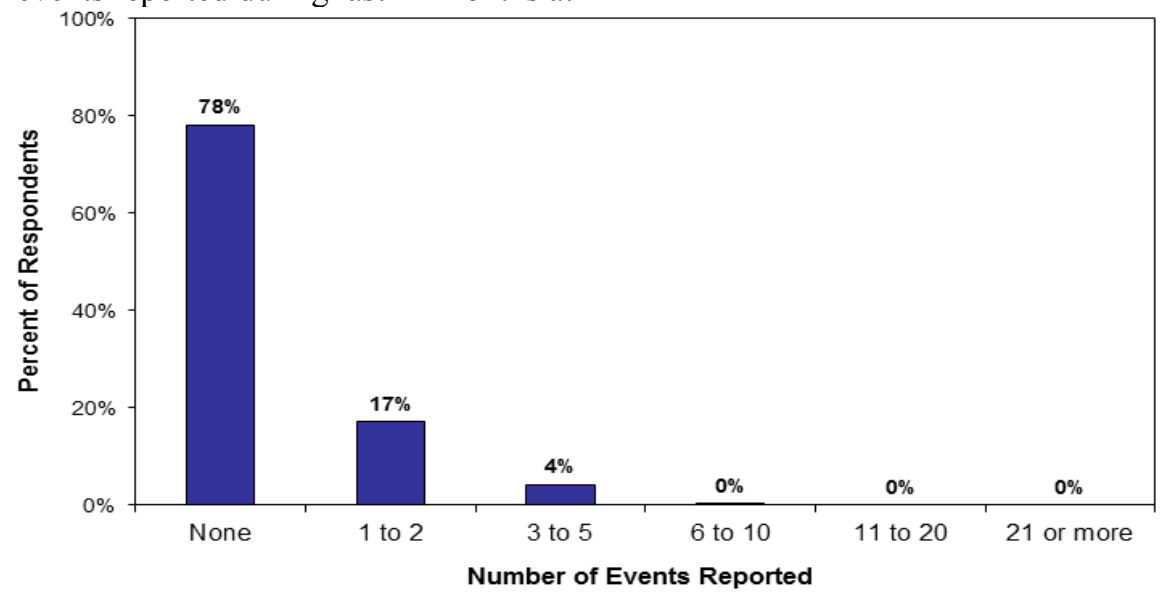

\section{Discussion and limitation}

Note1: Total percentage does not add to $100 \%$ due to rounding

A composite score summarizes how respondents answered group of items that all measure the same thing. The composite is calculated by averaging percentage of positive response on each item that is included in the composite. For the 12 patient safety culture dimensions of the HSOPSC survey was responded positively with an average rate of $56 \%$, lower than that of the Agency for Healthcare Research and Quality (AHRQ) data (65\%), in 2018 (25). Our study has found four comparable average positive score in comparison with the mean composite scores against the international benchmark. Those are: organizational learning and continuous improvement; overall perception of patient safety; teamwork across units; and, handoffs and transitions with the score obtained from US hospitals. The highest positive response rate was scored by the dimension "Teamwork within units", that was equal to the findings in the US. Furthermore, the findings reflected that most of them perceived that they were being supported and respected in their units. "Staffing" was the dimension with the lowest percentage of positive responses. From this study, it is evident that respondents believe that availability of adequate number of staff and supervisors non-punitive response to error play a major role in establishing patient safety at THM.

Non-punitive response to error dimension denotes the extent to which staff feels that their mistakes and event reported are not used against them and nothing is inserted into their personnel files in relation to the mistakes. According to the study this dimension scored the second lowest score (25\%) (Figure: 4$)$.

Figure 4: The mean patient safety culture composite scores of THM and database hospitals.

Note 1: The following formula was used to calculate the composite level percentage of positive responses : [number of positive responses to items in the composite / total number of responses to the items (positive, natural and negative) in the composite $\mathrm{X} 100$. The sum of patient safety grades of 'excellent' and 'very good' for THM is 47\% (Figure 5). This is below that of 'acceptable'. This finding is not healthy because THM is the only tertiary referral center for the Southern Sri Lanka for maternity care. Five percent of respondents had indicated that the overall patient safety is poor or failing. This might be a tip of an ice-berg that hospital upper management has to consider seriously. The sum of patient safety grades of 'excellent' or 'very good' for database hospital is seventy seven percent. The second most Sri Lankan's government budgetary allocation goes to the health. In addition, Sri Lankan health system is one of the leading health systems in South-east Asia. Therefore, patient safety grades has to be comparable with database hospitals although those hospitals are located in a develop country.

www.scirj.org

(C) 2020, Scientific Research Journal

http://dx.doi.org/10.31364/SCIRJ/v8.14.2020.P0420759

This publication is licensed under Creative Commons Attribution CC BY. 


\section{Figure 5: Overall patient safety grade and Percentage of respondents at THM compared to USA.}

In any hospital, patient safety and the patient safety culture of the hospital can only improve if adverse events are reported and analyzed. This study shows that there is significant reluctance to report adverse events because seventy eight percent of respondents had not reported any adverse event during last 12 months (Figure 3). This could be due to: only few incidents occurred during past 12 months, which is unlikely; respondents are afraid of reporting thinking that there will be punishment attached to it; something related to respondents attitude toward the incident reporting. Perceived punishment could be a possible reason because patient safety composite 'non-punitive response to error' got a very low percentage of 25\% (Figure 1). The Institute of Medicine (26) has shown the challenges healthcare organizations facing when moving toward the protective health system; that is, moving from shame and blame culture to a culture where errors are not considered as personal failures but as chance to create error free health care systems. The only way to encourage reporting adverse events is education and eliminating the blame culture.

On the other hand, $21 \%$ of responded 1-5 incidents during last 12 months. There are incidents that hospital staff is legally bound to report such as falling from bed. The observed $21 \%$ might be one that is legally bound to report.

Ministry of Health introduced an adverse event reporting system in recent past. However, the system did not establish as expected. This explains why health and safety programs are failing when it introduced without assessing and correcting health and safety culture, that is, employees belief and attitudes toward the safety of patient.

\section{Limitations}

It was acknowledged that the study faced many limitations. Firstly, although the sixty eight response rate is an adequate response rate for this kind of data collection method, non-responders may have biased the results (Only 35\% of clinicians had responded in this study). Secondly, the chief investigator of this study is the Head of the institution in this hospital; therefore, there is a tendency that responders might have responded favorably. Thirdly, some respondents might not have understood the some questions or misinterpreted.

\section{Conclusion and recommendation}

It has pointed out that assessment of patient safety culture is a good initiative to improve patient safety culture at THM (19). The HSOPSC tool is a practical avenue to understand the health and safety culture in THM when initiating health and safety programs in order to understand the health the critical areas that should be focused. The result of this study show that, in general, hospital staff of THM feels positively towards patient safety culture within the hospital. In addition, THM should enhance the education and should move towards a blame-free culture to improve the adverse event reporting. The showed discrepancies between US data and the THM data suggest that cultural uniqueness is an important factor to be concern when the safety culture measurement tools are using in different cultural settings.

References

1. World Health Organization, Introductory online course for patient safety research. Available from: https://www.who.int/patientsafety/research/online_course/en/

2. Alahmadi H.A. Assessment of patient safety culture in Saudi Arabian Hospital, British Medical Journal. 2009

3. WHO. Working together for health: the world health report 2006. Geneva, Switzerland; WHO Press, 2006.

4. Brennan TA, Leape LL, Laird NM, et al. Incidence of adverse events and

negligence in hospitalized patients: results of the Harvard Medical Practice

Study I. New England Journal of Medicine, 1991;324:370-7.

5. Kohn LT, Corrigan JM, Donaldson MS, ed. To err is human: building a safer health system. Washington, DC: National Academy Press, 1999.

6. Donaldson L, An Organization with Memory. London, UK: Department of Health Services, 2000.

7. World Health Organization. Fifty - fifth world health assembly 2002. Geneva, Switzerland; WHO Press, 2002.

8. World Health Organization. World Alliance for Patient safety 2005. Geneva, Switzerland; WHO Press, 2005.

9. World Health Organization. First Global Patient Safety Challenge "Clean Care is Safer Care" 2005 - 2006. Geneva, Switzerland; WHO Press, 2005.

10. Pronvost PJ, Weast B, Holzmullar CG, et al. Evaluation of the culture of safety: survey of clinicians and mangers in an academic center. Quality and Safety in Health Care 2003; 12:405-10.

11. Piotrowski MM, Hinshaw DB. The safety checklist program: creating a culture of safety in intensive care units. Jt Comm J Qual Improv 2002; 28: 306-15.

12. Wong P, Helsinger D, Petry J. Providing the right infrastructure to lead the culture change for patient safety. Jt Comm J Qual Improv 2002; 28: 363-72.

13. Krumberger JM. Building a culture of safety. RN2001; 64:32ac2-32ac3.

14. Pizzi LT, Goldfarb NI, Nash DB. Promoting a culture of safety. In: Shojana KG, Duncan BW, McDonald KM, eds. Evidence Report/Technical Assessment No. 43, Making health care safer: a critical analysis of patient safety practices. AHRQ Publication No. 01-E058. Agency for Healthcare Research and Quality. 2001. http://www.ahrq.gov/clinic/ptsafety/chap40.htm

www.scirj.org

(C) 2020, Scientific Research Journal

http://dx.doi.org/10.31364/SCIRJ/v8.i4.2020.P0420759

This publication is licensed under Creative Commons Attribution CC BY. 
15. Wakefield BJ, Blegen MA, Uden-Holman T, et al. Organization culture, continuous quality improvement, and medication administration error reporting. Am J Med Qual 2001; 16:128-34. 272.

16. Shortell SM, Jones RH, Rademaker AW, et al. Assessing the impact of total quality management and organizational culture on multiple outcomes of care for coronary artery bypass graft surgery patients. Med care 2000; 38:207-17.

17. World Health Organization, Global priorities for research in patient safety. Available from: http://www.who.int/patientsafety/research/priorities [Accessed on 20th June 2016].

18. Neale, G, Woloshynowych, M, Vincent, C. Exploring the causes of adverse events in NHS hospital practice. Journal of the Royal Society of Medicine 2000; 94: 322-330.

19. World Health Organization, Patient safety. Available from: http://www.who.int/patientsafety/en/ (n.d.).

20. Agency for Healthcare Research and Quality, Introduction. Available from: http://www.ahrq.gov/professionals/qualitypatientsafety/patientsafetyculture/hospital

21. Reason J. Managing the risks of organizational accidents. Burlington (VT): Ashgate, 2000.

22. Hoffman D, Marks B. An investigation of the relationship between safety climate and medication errors as well as other nurse and patient outcomes. Personal Psychology 2000 (4): 847-69.

23. Fedi EJ, Farheen S, Nereo AG. Diana J, Ayman A. Patient safety culture in a large teaching hospital in Riyadh: baseline assessment, comparative analysis and opportunities for improvement. BMC Health Service Research. 2014; 14:122 DOI: $10.1186 / 1472-6963-14122$.

24. Martin AM, Michael D. Medical error - third leading cause of death in US. British Medical Journal. 2016 (35): 1-5.

25. Katherine JJ, Anne S. Liyan X, Junfeng S, Keith M. The AHRQ hospital survey on patient safety culture: A tool to plan and evaluate patient safety programs. Available on: http://www.ahrq.gov/downloads/pub/advances2/vol2/advances-jones_29.pdf

26. Amarapathy S, Sridharan S, Perera R, Handa Y. Factors affecting patient safety culture in a tertiary care hospital in Sri Lanka. International Journal of Scientific \& Technology Research. 2013; 2(3).

27. Sorra J, Gray L, Streagle S, et al. AHRQ Hospital Survey on Patient Safety Culture: User's Guide. Available on: http://www.ahrq.gov/professionals/qualitypatientsafety/ patientsafetyculture/hospital/index.html

28. Nieva VF, Sorra J; Safety culture assessment: a tool for improving patient safety in health care organization. Quality and Safety in Health Care. 2003; 12(Suppl. 2): 17-23.

29. Hospital survey on patient safety culture: 2018 user database report. Agency for Health care Research and Quality. Available from: https://psnet.ahrq.gov/resources/resource/31942/Hospital-Survey-on-Patient-Safety-Culture-2018-User-Database-Report. Accessed 15 June 2019.

30. Kohn LTCT, Donaldson MS, editors. To err is human: building a safer health system. Washington, DC: National Academy Press; 2000.

www.scirj.org

(C) 2020, Scientific Research Journal

http://dx.doi.org/10.31364/SCIRJ/v8.i4.2020.P0420759

This publication is licensed under Creative Commons Attribution CC BY. 